\title{
Abnormal Pyruvate and $\alpha$-Ketoglutarate Dehydrogenase Complexes in a Patient with Lactic Acidemia
}

\author{
YASUHIRO KURODA, JEFFREY J. KLINE, LAWRENCE SWEETMAN, WILLIAM L. NYHAN, AND \\ TED D. GROSHONG \\ Department of Pediatrics, University of California San Diego, La Jolla, California, USA, and Department of Child \\ Health, (J. J. K., T. D. G.) University of Missouri Medical Center, Columbia, Missouri, USA
}

\begin{abstract}
Summary
Activities of pyruvate decarboxylase (PDC), $\alpha$-ketoglutarate decarboxylase (KGDC) and both the pyruvate and $\alpha$-ketoglutarate dehydrogenase complexes (PDH complex and KGDH complex) were measured, and kinetic properties of PDC were studied in fibroblasts derived from normal individuals and from a 2-yr-old girl with congenital lactic acidemia and severe retardation of growth and development. The activities of PDC, KGDC, PDH complex, and KGDH complex in the patient were $1.12 \pm 0.12,2.33 \pm 0.42$, $9.00 \pm 0.50$, and $16.46 \pm 1.57$ and in controls $3.10 \pm 0.16,5.36 \pm$ $0.56,24.13 \pm 1.61$ and $44.95 \pm 3.72 \mathrm{nmole} / \mathrm{mg}$ protein $/ \mathrm{hr}$. The optimum pl $(6.0)$ and Michaelis constants $(\mathrm{Km})$ for pyruvate of PDC $\left(1.0-1.6 \times 10^{-5} \mathrm{M}\right)$ were similar in fibroblasts of the patient and controls. PDC activity was more sensitive to denaturation by heat in the fibroblasts of the patient than those from controls, while heat denaturation curves of KGDC were similar in the patient and control. Higher concentrations of thiamine pyrophosphate (TPP) were required to protect PDC from heat denaturation in the patient. TPP was more easily removed from PDC in the patient than in the control by washing the fibroblasts with alkaline buffer. These results suggest that the PDC enzyme of the patient is in an altered molecular form, to which TPP is loosely bound. This particular constellation of abnormalities has not previously been reported in patients with lactic acidemia.
\end{abstract}

\section{Speculation}

The defective activity of PDC, KGDC, PDH, and KGDH complexes in this patient might be the result of a mutation in the gene for an enzyme subunit common to both PDC and KGDC.

Congenital lactic acidemia is now known to be heterogeneous and to be caused by genetically determined defects in the activities of a variety of enzymes. These include deficiencies of the PDH complex $(1,3,6,22,26)$, pyruvate carboxylase (4), glucose-6phosphatase (24), and fructose diphosphatase (21). It is also seen in patients with methylmalonic acidemia $(13,17)$, and Leigh's subacute necrotizing encephalomyelopathy (29). Hereditary deficiencies in the PDH complex or the KGDH complex have been described in over 25 patients with lactic acidosis. The PDH complex is a multienzyme system which is comprised of PDC, dihydrolipoyltransacetylase and dihydrolipoyldehydrogenase (14). PDC contains TPP and exists in an active (nonphosphorylated) and an inactive (phosphorylated) form. The conversion from the active to the inactive form is catalyzed by a kinase, and the conversion from the inactive to the active form is catalyzed by a magnesium dependent phosphatase (18).

We have investigated the $\mathrm{PDH}$ and $\mathrm{KGDH}$ complexes in fibroblasts from a patient with congenital lactic acidosis and severe retardation of growth and development. Assays of enzyme activity revealed that both $\mathrm{PDH}$ and $\mathrm{KGDH}$ complexes were partially deficient. The thiamine-dependent first enzyme of the PDH complex, PDC, had altered kinetic properties.

\section{CASE REPORT}

M. S. was a 2-yr-old caucasian girl who had had intermittent lactic acidosis and severe retardation of growth and development. She was admitted first at 14 months to the University of Missouri Medical Center because of failure to thrive.

Two paternal male cousins had had profound mental retardation and died at an early age. Two younger siblings of this patient also died at an early age. One had brain injury secondary to birth trauma. The other had the same syndrome as this patient and died of sepsis.

On examination, she was a pale, retarded, floppy infant who appeared younger and smaller than her age. She was hyperventilating. Examination of the chest revealed no rales or rhonchi. The extremities were hypotonic, but all four moved well. Deep-tendon reflexes could not be obtained. She was able to sit, but did not walk. There was no evidence of ataxia.

She was found to have lactic acidosis $(118 \mathrm{mg} / \mathrm{dl})$. The serum $\mathrm{CO}_{2}$ content was $6 \mu \mathrm{Eq} /$ liter and the $\mathrm{pH} 7.10$. The concentration of lactic acid in the blood remained high, between 55 and 118 $\mathrm{mg} / \mathrm{dl}$ (normal $3-12 \mathrm{mg} / \mathrm{dl}$ ) while the concentration of pyruvate ranged from $2.5-3.0 \mathrm{mg} / \mathrm{dl}$ (normal $0.3-0.7 \mathrm{mg} / \mathrm{dl}$ ). On screening for metabolic disease, samples of urine were found to contain large amounts of ketones, keto acids, and alanine. The excretion of alanine was $0.14 \mathrm{mg} / \mathrm{mg}$ of creatinine (normal $0.025-0.088$ ). Quantitative analysis of the organic acids showed four major elevations, hippuric, acetoacetic, 3-hydroxybutyric, and lactic acids. The values were $99.4,178.0,280.0$, and $797.0 \mu \mathrm{moles} / \mathrm{mg}$ creatinine, respectively. The excretions of $\alpha$-ketoglutaric acid and the branched-chain keto acids and amino acids were not elevated. A biopsy of the skin was obtained with informed consent for evaluation of PDC and PDH activities in cultured fibroblasts.

\section{MATERIALS AND METHODS}

\section{CHEMICALS}

$1-{ }^{14} \mathrm{C}$-pyruvate (sodium salt, specific activity $5.82-8.92 \mathrm{mCi}$ / mmole) and $1-{ }^{14} \mathrm{C}-\alpha$-ketoglutarate (sodium salt, specific activity $54.1 \mathrm{mCi} / \mathrm{mmole}$ ) were purchased from the New England Nuclear Corporation. All other chemicals used were of highest available purity.

\section{CULTURED SKIN FIBROBLASTS}

Skin fibroblasts were grown in Eagle's Minimal Essential Media at $\mathrm{pH} 7.2-7.4$ with $10 \%$ fetal calf serum. Cells from the patient and controls were harvested on the day of each experiment with activated trypsin versene while in the log phase of growth. 
ENZYME ASSAYS

Cells were washed twice with $50 \mathrm{mM}$ Tris- $\mathrm{HCl}, \mathrm{pH} 7.4$, containing $0.105 \mathrm{M} \mathrm{NaCl}$. Washed cell pellets were suspended in cold distilled water to a concentration of $4-6 \times 10^{6}$ cells $/ \mathrm{ml}$ and kept in ice for $20 \mathrm{~min}$. Then, $4.0 \mathrm{ml}$ of the cell suspension was sonicated. All of the PDC activity was detected in the supernatant after centrifugation which would have removed unruptured cells. The activity of PDC was measured by the method of Blass et al. (1) except that the concentration of $\mathrm{MgCl}_{2}$ was increased to $10 \mathrm{mM}$, the final incubation volume was scaled up by a factor of 5 to 0.7 $\mathrm{ml}$ and ${ }^{14} \mathrm{CO}_{2}$ was collected in $3 \mathrm{~N} \mathrm{NaOH}$ after acidification of the incubation mixture. The activity of KGDC was measured under the same conditions, but with $\alpha$-ketoglutarate instead of pyruvate as substrate. In the kinetics studies on PDC and KGDC, sonicates of fibroblasts were preincubated with $5.7 \mathrm{mM} \mathrm{MgCl}_{2}$ in $27.7 \mathrm{mM}$ potassium phosphate buffer, pH 6.0, for $20 \mathrm{~min}$ at room temperature before assay for maximum activation by the phosphatase. In the heat denaturation study, the samples were heated after the addition of $0.13 \mathrm{ml}$ of $0.75 \mathrm{M}$ potassium phosphate buffer, $\mathrm{pH} 7.5$, to $1.083 \mathrm{ml}$ of the preincubated sonicates in order to adjust the $\mathrm{pH}$ to 7.1. The reaction mixture for the enzyme assay contained $1.4-1.6 \mathrm{mM} \mathrm{MgCl}_{2}$ in these studies.

The activities of the PDH and KGDH complexes were measured by the method of Blass et al. (2) except that ${ }^{14} \mathrm{CO}_{2}$ was collected in $3 \mathrm{~N} \mathrm{NaOH}$ after acidification of the incubation mixture. Cytochrome c oxidase was measured spectrophotometrically (28) in sonicates of fibroblasts. Protein was measured by the method of Lowry et al. (16) using bovine albumin as standard.

\section{PROCEDURE FOR REMOVING TPP FROM THE ENZYMES}

Fibroblasts were suspended in $0.1 \mathrm{M}$ potassium phosphate buffer $\mathrm{pH} 8.8$ and the suspension was stirred for $5 \mathrm{~min}$ in ice. Then, the fibroblasts were separated by centrifugation at $7,710 \times$ $g$ and washed once with water. The final sediment was suspended in water and sonicated. This procedure has been shown to dissociate TPP from PDC of yeast, producing a requirement for added TPP in the assay (20).

\section{RESULTS}

The activities of both the PDH and KGDH complexes were lower in fibroblasts from the patient with congenital lactic acidemia than from controls (Table 1). The mean PDH activity (nmole/ mg protein/hr) for the patient was 9.00 (range 7.63-10.00) compared to the mean values of 24.00 and 24.20 (range of individual assays 18.01-29.83) for the controls. The mean $\mathrm{KGDH}$ activity was 16.46 (range 13.39-19.97) compared to 40.00 and 47.42 (range of individual assays 34.90-61.48) for the controls. There was no overlap in the individual assay values for the patient and controls, and both PDH and KGDH were $37 \%$ of the mean of the controls. The differences were significant at $P<0.001$. The activities of PDC and KGDC which are the first components of the dehydrogenase complexes were also low in fibroblasts from the patient (Table 1). The mean PDC activity (nmole/mg protein $/ \mathrm{hr}$ ) for the

Table 1. Enzyme activities in disrupted fibroblasts from patient and controls ${ }^{1}$

\begin{tabular}{|c|c|c|}
\hline & \multicolumn{2}{|c|}{ Activity (nmole/mg protein $/ \mathrm{hr}$ ) } \\
\hline & Controls & Patient \\
\hline PDC & $3.10 \pm 0.16(20)$ & $1.12 \pm 0.12(15)^{2}$ \\
\hline KGDC & $5.36 \pm 0.57(10)$ & $2.33 \pm 0.42(9)^{2}$ \\
\hline PDH & $24.13 \pm 1.61(6)$ & $9.00 \pm 0.50(4)^{2}$ \\
\hline KGDH & $44.95 \pm 3.72(6)$ & $16.46 \pm 1.57(4)^{2}$ \\
\hline Cytochrome c oxidase & $2130 \pm 164(9)$ & $1786 \pm 134(3)^{3}$ \\
\hline
\end{tabular}

\footnotetext{
' Values are means \pm SEM. with the total number of assays shown in parentheses. There were three control subjects in assays for PDC and cytochrome $\mathrm{c}$ oxidase and two for the others.

${ }^{2} P<0.001$

${ }^{3}$ Not significant.
}

patient was 1.12 (range $0.44-1.88$ ) compared to the mean values of 3.72, 2.73, and 2.95 (range of individual assays 1.81-4.67) for the controls. The mean KGDC activity was 2.33 (range 1.04-4.89) compared to 6.36 and 5.11 (range of individual assays 3.57-8.23) for the controls. Although the ranges of individual values of the patient and controls overlapped, the mean PDC activity was $36 \%$ and the mean KGDC was $40 \%$ of the mean of the controls and the differences were significant at $P<0.001$. Cytochrome c oxidase activity was slightly decreased in the patient ( $84 \%$ of control), but the difference was not significant.

In study of the kinetic properties of these enzymes, PDC activity was found to be more sensitive to denaturation by heat in the fibroblasts from the patient than those from controls (Fig. 1). Incubation for $5 \mathrm{~min}$ at $46.5^{\circ} \mathrm{C}$ led to complete loss of activity in the patient, while there was still $30 \%$ of original activity in controls. In contrast, the heat denaturation curve of KGDC did not differ significantly from control (Fig. 1).

PDC was completely protected from heat denaturation by the addition of $0.7 \mathrm{mM} \mathrm{TPP}$ in both patient and control (Fig. 2). However, higher concentrations of TPP were required to protect the PDC of the patient from heat denaturation. TPP was more easily removed from PDC of the patient than of the control by washing the cells with alkaline buffer (Table 2). This was determined by assay of the enzyme in washed and unwashed cells with and without added TPP. PDC was virtually absent in washed cells of the patient without added TPP and increased markedly with the addition of TPP to the maximum level observed in unwashed cells.

The pH optimum curve of PDC activity was similar in the fibroblasts from the patient and control. The enzyme had a $\mathrm{pH}$ optimum in the region of $\mathrm{pH}$ 6.0. The Michaelis constant $(\mathrm{Km})$ of PDC for pyruvate was $1.0-1.6 \times 10^{-5} \mathrm{M}$ in fibroblasts from the patient and was not different in patient and control (Fig. 3).

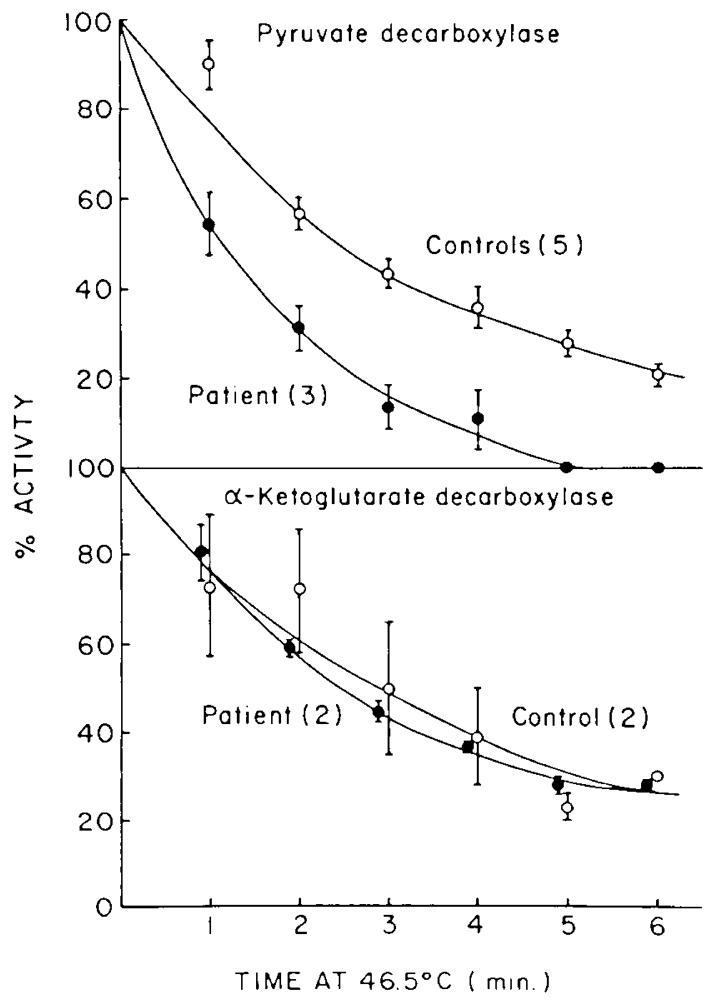

Fig. 1. Denaturation of pyruvate decarboxylase by heat. Disrupted fibroblasts were incubated at $46.5^{\circ} \mathrm{C}$ for different times. Enzyme activities were assayed in duplicate at $30^{\circ} \mathrm{C}$. Activity is expressed as a percent of activity of disrupted fibroblasts kept at $0^{\circ} \mathrm{C}$. One and three control subjects were studied for heat denaturation of $\alpha$-ketoglutarate and pyruvate decarboxylase, respectively. Numbers of assays are in parentheses. Vertical bars in the figure designate means \pm SEM. 


\section{DISCUSSION}

The conversion of pyruvate to acetyl-CoA is catalyzed by the multienzyme, PDH complex. The first component, PDC, is a thiamine-dependent enzyme. Deficiency in the activity of the PDH complex leads to accumulation of pyruvate which is promptly converted to lactate and alanine.

Our patient had congenital lactic acidemia and activities of PDC, KGDC, and both PDH and KGDH complexes were decreased in cultured fibroblasts. Furthermore, properties different from those of the normal enzyme were demonstrated for PDC of the patient. PDC activity was more sensitive to denaturation by heat. Higher concentration of TPP were required to protect PDC from heat denaturation in the patient and TPP was more easily removed from the PDC of the patient. However, the Michaelis constants $(\mathrm{Km})$ for pyruvate and $\mathrm{pH}$ optimum were similar in patient and controls. The data suggest that the PDC of the patient is an altered molecular form, to which TPP is loosely bound. It has been suggested that fibroblasts contain more than one form of PDC because of inflections in the substrate-activity curves (1). Inflections were not found in our studies in either patient or controls.

Hereditary deficiencies in the PDH complex or the $\mathrm{KGDH}$ complex have been described in over 25 patients with lactic acidosis. Most patients have had mild to severe neurologic disease.

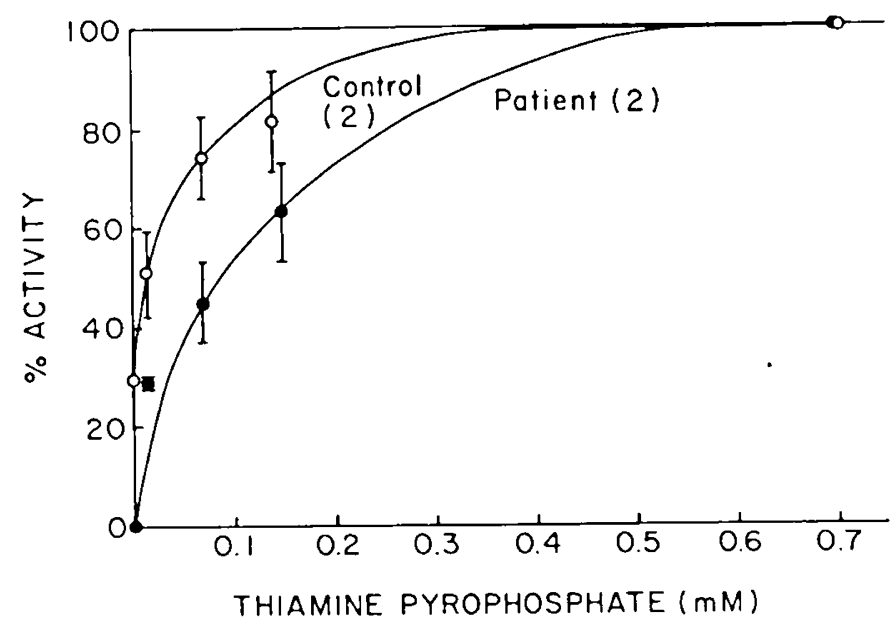

Fig. 2. Protective effect of thiamine pyrophosphate on heat denaturation of pyruvate decarboxylase. Disrupted fibroblasts were incubated with various concentration of thiamine pyrophosphate at $46.5^{\circ} \mathrm{C}$ for $5 \mathrm{~min}$ and enzyme activities were assayed in duplicate as described in the method. Activity is expressed as a percent of activity of disrupted fibroblasts at $0^{\circ} \mathrm{C}$. Vertical bars in the figure designate means \pm SEM. Numbers of assays are in parentheses.
Defects in both the PDH and $\mathrm{KGDH}$ complexes have been reported in cultured fibroblasts from a patient with lactic acidosis (12) and five patients with Friedreich's ataxia (2). Blood concentrations of pyruvate and lactate were not elevated in the patients with Friedreich's ataxia. In one of five patients with Friedreich's ataxia, activity in the potassium ferricyanide-linked assay for PDC was also decreased, but the activity of KGDC was not determined (2). Because each complex is built of three enzymes and one enzyme, dihydrolipoyldehydrogenase (LPD) is the same protein in both complexes in mammals $(25)$ and in bacteria $(9,10,11,15)$, it has been suggested that a mutation in LPD would account for a reduction in the activity of both complexes in these patients. However, a recent study found normal PDH and lipoamide dehydrogenase in fibroblasts from six patients with Friedreich's ataxia (19). Recently, deficiency of LPD was found in tissues of a patient with congenital lactic acidosis with deficiencies of $\mathrm{PDH}$ and $\mathrm{KGDH}$, but normal PDC and KGDC (23). In our patient, the activities of the PDH and KGDH complexes were decreased, but the evidence for molecular alteration in PDC and low activities of PDC and KGDC argue against a defect in LPD. Further, the patient with LPD deficiency had branched-chain amino acidemia and decreased activity of branched-chain keto acid dehydrogenase indicating that the same LPD is common to pyruvate, $\alpha$-ketoglutarate, and branched-chain keto acid dehydrogenases (27). The concentrations of the branched-chain amino acids and keto acids in our patient were normal, indicating that the branched-chain keto acid dehydrogenase was normal, although this was not assayed in the fibroblasts.

PDC from bovine heart and kidney and pigeon breast muscle

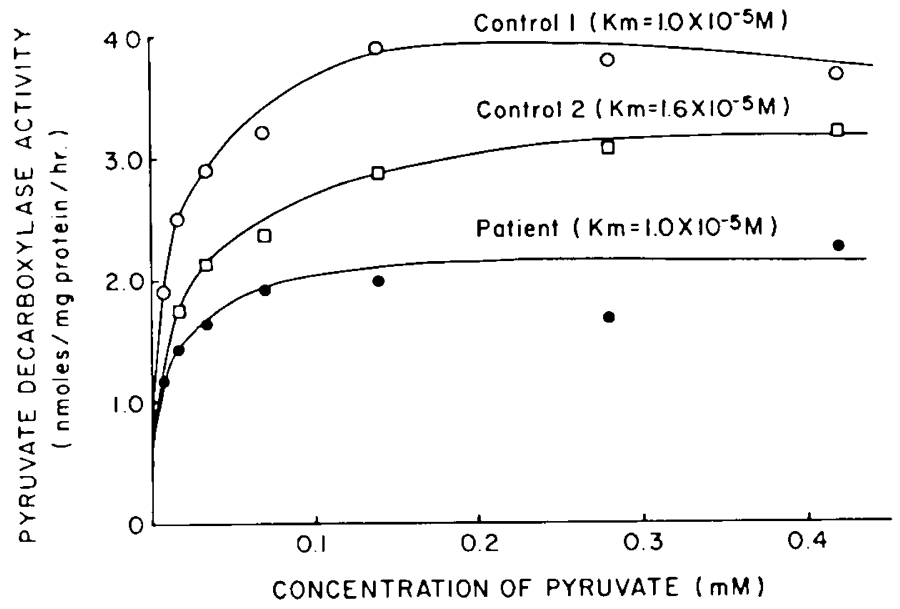

Fig. 3. Pyruvate decarboxylase activity in fibroblasts from patient and controls at different concentrations of pyruvate. Pyruvate decarboxylase activity was measured in duplicate at each concentration of pyruvate.

Table 2. Alkaline washing of intact fibroblasts from patient and

Table 2. Alkaline washing of intact
control

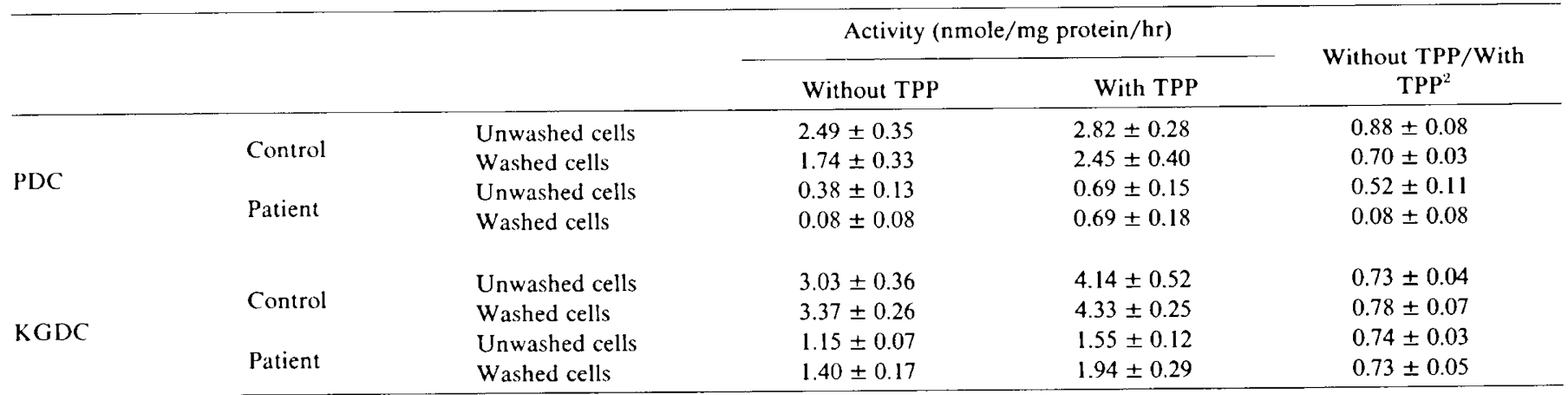

\footnotetext{
I Intact cells were washed and activities were measured with and without $0.14 \mathrm{mM}$ thiamine pyrophosphate. Values are means \pm SEM of four
} experiments.

${ }^{2}$ The ratios (without TPP/with TPP) are the mean values \pm SEM of the ratios from four experiments. 
appears to be a tetramer of subunit structure $\alpha_{2} \beta_{22}$. The $\alpha$ subunit probably binds TPP and $\mathrm{Mg}^{2+}$ and catalyzes the decarboxylation of pyruvate to yield 2- $\alpha$-hydroxy-ethyl TPP whereas the $\beta$ subunit may catalyze the subsequent reductive acetylation of the oxidized lipoic acid moieties on the transacetylase $(5,7)$. It is also supposed that KGDC from pigeon breast muscle has several subunits differing in their molecular weight, and different oligomeric forms of the enzyme represent certain combinations of the enzyme subunits (8).

It is not at all likely that the patient represents two separate mutations in pyruvate and $\alpha$-ketoglutarate dehydrogenases. The mechanism by which a single mutational event could provide molecular alteration in PDC and defective activities of KGDC and the KGDH complex is far from clear. A possible hypothesis would be that there is a mutation in an $\alpha$ subunit common to PDC and KGDC. If this were true, the substrate specificity for pyruvate or $\alpha$-ketoglutarate might then be conferred by different $\beta$ subunits. Such a mutation might not alter the resistance of KGDC to heat, but alter that of PDC to heat along with its binding of TPP. An alternate hypothesis would be that mutation in a gene for PDC somehow interferes with expression of the gene for KGDC.

\section{REFERENCES AND NOTES}

1. Blass, J. P., Avigan, J., and Uhlendorf, B. W.: A defect in pyruvate decarboxylase in a child with an intermittent movement disorder. J. Clin. Invest., 49: 423 (1970).

2. Blass, J. P., Kark, R. A. P., and Menon, N. K.: Low activities of the pyruvate and oxoglutarate dehydrogenase complexes in five patients with Friedreich`s ataxia. N. Engl. J. Med., 295: 62 (1976)

3. Blass, J. P., Schulman, J. D., Young. D. S., and Home, E.: An inherited defect affecting the tricarboxylic acid cycle in a patient with congenital lactic acidosis. J. Clin. Invest., 5I: 1845 (1972).

4. Brunette, M. G., Delvin. E., Hazel, B., and Scriver, C. R.: Thiamine responsive acidosis in a patient with deficient low- $\mathrm{Km}$ pyruvate carboxylase activity in liver. Pediatrics, 50: 702 (1972).

5. Denton, R. M., Randle, P. J., Bridges, B. J., Cooper, R. H., Kerbey, A. L., Pask, H. T., Seversen, D. L., Stansbie. D., and Whitehouse, S.: Regulation of mammalian pyruvate dehydrogenase. Mol. Cell. Biochem.. 9: 27 (1975).

6. Farrell, D. F. Clark. A. F., Scott, C. R., and Wennberg. R. P.: Absence of pyruvate decarboxylase activity in man: a cause of congenital lactic acidosis. Science, 187: 1082 (1975)

7. Furuta, S., Shindo, Y., and Hashimoto, T.: Purification and properties of pigeon breast muscle a-keto acid dehydrogenase complexes. J. Biochem., 81 : 1839 (1977).

8. Gomazkova, V. S., and Severin. S. E.: Multiplicity of decarboxylase component of a-ketoglutarate dehydrogenase complex from pigeon breast muscle. Biokhimiya, 37: 637 (1972)

9. Guest, J. R.: Gene-protein relationships of the $\alpha$-keto acid dehydrogenase complexes of Escherichia coli K12: Chromosomal location of the lipoamide dehydrogenase gene. J. Gen. Microbiol.. 80: 523 (1974).

10. Guest, J. R., and Creaghan, I. T.: Further studies with lipoamide dehydrogenase mutants of Escherichia coli K12. J. Gen. Microbiol., 81: 237 (1974).

11. Guest, J. R., and Creaghan, I. T.: Gene-protein relationships of the $\alpha$-keto acids dehydrogenase complexes of Escherichia coli $\mathrm{K} 12$ : Isolation and characterization of lipoamide dehydrogenase mutants. J. Gen. Microbiol., 75: 197 (1973).

12. Haworth, J. C.. Perry, T. L., Blass, J. P., Hansen, S., and Urquhart, N.: Lactic acidosis in three sibs due to defects in both pyruvate dehydrogenase and $\alpha$ ketoglutarate dehydrogenase complexes. Pediatrics, 58: 564 (1976).

13. Hsia, Y. E., Lilljequist, A. C., and Rosenberg, L. E.: Vitamin B $_{1: 2}$ dependent methylmalonic aciduria: amino acid toxicity, long chain ketonuria, and protective effect on vitamin $B_{12}$. Pediatrics, 46: 497 (1970).

14. Koike, M., Reed, L. J., and Carroll, W. R.: $\alpha$-keto acid dehydrogenation complexes. IV. Resolution and reconstitution of the Escherichia coli pyruvate dehydrogenation complex. J. Biol. Chem., 238: 30 (1963).

15. Langley, D., and Guest, J. R.: Biochemical and genetic characteristics of deletion and other mutant strains of Salmonella typhimurium LT2 lacking $\alpha$-keto acid dehydrogenase complex activities. J. Gen. Microbiol., 82: 319 (1974).

16. Lowry, O. H., Rosebrough, N. J., Farr, A. L., and Randall, R. J.: Protein measurement with the folin phenol reagent. J. Biol. Chem., 193: 265 (1951).

17. Lindblad, B., Lindblad, B. S., Olin, P., Svanberg. B., and Zetterstron, R.: Methylmalonic acidemia: A disorder associated with acidosis, hyperglycinemia. and hyperlactemia. Acta Paediatr. Scand., 57: 417 (1968).

18. Linn, T. C.. Pettit, F. H., and Reed, L. J.: $\alpha$-keto acid dehydrogenase complexes $X$. Regulation on the activity of the pyruvate dehydrogenase complex from beef kidney mitochondria by phosphorylation and dephosphorylation. Proc. Natl. Acad. Sci., 62: 234 (1969).

19. Melancon, S. B., Potier, M., Dallaire, L., Fontaine, G., Grenier, B., Lemieux, B. Geoffroy. G., and Barbeau, A.: Lipoamide dehydrogenase in Friedreich's ataxia fibroblasts. Canad. J. Neurol. Sci., 5: 115 (1978).

20. Morey, A. V., and Juni, E.: Resolution, reconstitution, and other methods for the study of binding of thiamine pyrophosphate to enzymes. In: D. B. McCormick and L. D. Wright: Methods in Enzymology. Vol. 18. Vitamins and Coenzymes, Part A, p. 238 (Academic Press, New York and London, 1970).

21. Pagliara, A. S., Karl, I. E., Keating, J. P., Brown, B. I., and Kipnis, D. M. Hepatic fructose-1,6-diphosphatase deficiency, a cause of lactic acidosis and hypoglycemia in infancy. J. Clin. Invest., 51:2115 (1972).

22. Robinson, B. H., and Sherwood, W. G.: Pyruvate dehydrogenase phosphatase deficiency: a cause of congenital chronic lactic acidosis in infancy. Pediatr. Res., 9: 935 (1975).

23. Robinson, B. H., Taylor, J., and Sherwood, W. G.: Deficiency of dihydrolipoyl dehydrogenase (a component of the pyruvate and $\alpha$-ketoglutarate dehydrogenase complexes): a cause of congenital chronic lactic acidosis in infancy. Pediatr. Res., 11: 1198 (1977)

24. Sadeghi-Nejad, A., Presente, E., Binkiewize, A., and Senior, B.: Studies in type I glycogenesis of the liver: The genesis and disposition of lactate. J. Pediatr., 85: 49 (1974).

25. Sakurai, Y., Fukuyoshi, Y., Hamada, M., Hayakawa. T., and Koike, M.: Mammalian $\alpha$-keto acid dehydrogenase complexes. II. Nature of the multiple forms of pig heart lipoamide dehydrogenase. J. Biol. Chem.. 245: 4453 (1970).

26. Stromme, J. H., Borud, O., and Moe, P. J.: Fatal lactic acidosis in a newborn attributable to a congenital defect of pyruvate dehydrogenase. Pediatr. Res., 10: 60 (1976).

27. Taylor, J., Robinson. B. H., and Sherwood, G.: A defect in branched-chain amino acid metabolism in a patient with congenital lactic acidosis due to dihydrolipoyl dehydrogenase deficiency. Pediatr. Res., 12: 60 (1978).

28. Wharton, D. C., and Tzagalof, A.: Cytochrome oxidase from beef heart mitochondria. In: R. W. Estabrook and M. E. Pullman: Methods in Enzymology. Vol. 10, p. 245 (Academic Press, New York and London, 1967).

29. Worsley, H. E., Brookfield, R. W., Elwood, J. S., Noble, R. L., and Taylor, W. H.: Lactic acidosis with necrotizing encephalopathy in two sibs. Arch. Dis. Childhood, 40: 492 (1965).

30. The authors thank Mr. Charles D. Johnson for his expert help in culturing the fibroblasts.

31. The present address of Dr. Yasuhiro Kuroda is: Department of Pediatrics, Tokushima University. Tokushima, Japan.

32. This research was supported by U.S. Public Health Service grants HD 0460 from the National Institute of Child Health and Human Development. GM 17702 from the National Institute of General Medical Sciences, and RR 0028711 from the General Clinical Research Centers program of the Divisions of Research Resources, National Institutes of Health, Bethesda, MD, USA

33. Requests for reprints should be addressed to: Dr. Lawrence Sweetman, Department of Pediatrics M-009. University of California San Diego, La Jolla, CA 92093, USA.

34. Received for publication May 8, 1978

35. Accepted for publication August 10, 1978 